\title{
Hepatic Lipid Peroxidation In Vivo in Rats with Chronic Iron Overload
}

\author{
Bruce R. Bacon, anthony S. Tavill, Gary M. Brittenham, C. H. Park, and \\ Richard O. Recknagel, Departments of Medicine and Pathology, Case \\ Western Reserve University School of Medicine at Cleveland Metropolitan \\ General Hospital, Cleveland, Ohio 44109; Department of Physiology, Case \\ Western Reserve University School of Medicine, Cleveland, Ohio 44106
}

\begin{abstract}
A B S T R A C T Peroxidative decomposition of cellular membrane lipids is a postulated mechanism of hepatocellular injury in parenchymal iron overload. In the present study, we looked for direct evidence of lipid peroxidation in vivo (as measured by lipid-conjugated diene formation in hepatic organelle membranes) from rats with experimental chronic iron overload. Both parenteral ferric nitrilotriacetate (FeNTA) administration and dietary supplementation with carbonyl iron were used to produce chronic iron overload. Biochemical and histologic evaluation of liver tissue confirmed moderate increases in hepatic storage iron. FeNTA administration produced excessive iron deposition throughout the hepatic lobule in both hepatocytes and Kupffer cells, whereas dietary carbonyl iron supplementation produced greater hepatic iron overload in a periportal distribution with iron deposition predominantly in hepatocytes. Evidence for mitochondrial lipid peroxidation in vivo was demonstrated at all three mean hepatic iron concentrations studied $(1,197,3,231$, and 4,216 $\mu \mathrm{g} \mathrm{Fe} / \mathrm{g})$ in both models of experimental chronic iron overload. In contrast, increased conjugated diene formation was detected in microsomal lipids only at the higher liver iron concentration $(4,161 \mu \mathrm{g} \mathrm{Fe} / \mathrm{g})$ achieved by dietary carbonyl iron supplementation. When iron as either FeNTA or ferritin was added in vitro to normal liver homogenates before lipid extraction, no conjugated diene formation was observed. We conclude that the presence of conjugated dienes in the subcellular frac-
\end{abstract}

This work was presented in part at the Annual Meetings of the American Association for the Study of Liver Diseases, Chicago, IL, November 1981 and the American Gastroenterological Association, Chicago, IL, May 1982, and published in abstract form. 1981. Hepatology. 1: 493, and 1982. Gastroenterology. 82: 1221 .

Received for publication $16 \mathrm{July} 1982$ and in revised form 2 November 1982. tions of rat liver provide direct evidence of iron-induced hepatic mitochondrial and microsomal lipid peroxidation in vivo in two models of experimental chronic iron overload.

\section{INTRODUCTION}

Excess iron deposited chronically in hepatic parenchymal cells is associated with hepatic injury, fibrosis, and ultimately cirrhosis (1). These pathological changes occur in both hereditary hemochromatosis and in the various forms of secondary hemochromatosis. Despite clinical evidence for the toxicity of excess hepatocellular iron (2-5), the role of iron in the pathogenesis of liver injury has not been established experimentally (6).

Currently, the two favored hypotheses for the mechanism of hepatocellular injury in chronic iron overload are $(a)$ peroxidative damage to the lipid membranes of cellular organelles resulting in structural and functional alterations in cell integrity $(1,6,7)$ and $(b)$ lysosomal fragility resulting in the release of cell-damaging hydrolytic enzymes (1, 8-10). These are not mutually exclusive theories as lipid peroxidation may mediate the loss of lysosomal membrane integrity. Although ionic iron $\left(\mathrm{Fe}^{2+}, \mathrm{Fe}^{3+}\right)$ in vitro can initiate lipid peroxidation in isolated hepatocellular organelles (11-18), evidence that chronic iron overload results in hepatic lipid peroxidation in vivo has been limited to two reports in which increased malonic dialdehyde (MDA $^{1}$ was demonstrated in liver of rats that had received parenteral iron dextran $(19,20)$.

To assess the role of chronic iron overload in the promotion of hepatic lipid peroxidation in vivo, we

\footnotetext{
${ }^{1}$ Abbreviations used in this paper: FeNTA, ferric nitrilotriacetate; HSF, horse spleen ferritin; MDA, malonic dialdehyde; NTA, disodium nitrilotriacetate.
} 
examined subcellular fractions of liver from rats with chronic iron overload for the presence of lipid-conjugated dienes, the products of peroxidative breakdown of membrane polyunsaturated lipids. Two methods of experimental chronic iron overload were used: (a) parenteral administration of ferric nitrilotriacetate (FeNTA); and (b) supplementation of diets with $2.5 \%$ (wt/wt) carbonyl iron, a highly purified form of elemental iron. Parenteral administration of FeNTA produces homogeneous deposition of iron throughout the hepatic lobule in both hepatocytes and Kupffer cells. In contrast, supplementation of diets with carbonyl iron produces predominant hepatocellular iron deposition in a periportal distribution, a pattern analogous to that seen in human hereditary hemochromatosis.

\section{METHODS}

Animals. Male rats of the Sprague-Dawley strain were purchased from Zivic-Miller Laboratories, Inc. (Allison Park, PA). Rats were housed in polyethylene cages with stainless steel wire tops and were allowed diet and water ad lib. Rats that received parenteral FeNTA and those that were used for in vitro studies were maintained on Purina Lab Chow (Ralston Purina Company, Chicago, IL).

Chemicals. Disodium nitrilotriacetate (NTA) and horse spleen ferritin (HSF) were purchased from Sigma Chemical Co. (St. Louis, MO). Carbonyl iron (SF-special grade) was purchased from the GAF Corporation (New York). Carbonyl iron is an extremely pure form of elemental iron, $(>98 \%$ iron with $<0.8 \%$ carbon, $<0.3 \%$ oxygen, and $<0.9 \%$ nitrogen; Paulette Comis, GAF Corporation, personal communication), prepared by reacting iron at high temperatures with carbon monoxide to form gaseous iron pentacarbonyl, $\mathrm{Fe}(\mathrm{CO})_{5}$. This compound, on further heating, deposits metallic iron as submicroscopic crystals that form microscopic spheres $<5 \mu \mathrm{m}$ in size (21).

FeNTA administration. The method of May et al. (22) was followed. Rats were injected daily with iron (29 $\mathrm{mM})$ as FeNTA in doses of $2 \mathrm{mg} / \mathrm{kg}$ body weight i.p. for d 1-14, $5 \mathrm{mg} / \mathrm{kg}$ per $\mathrm{d}$ for $\mathrm{d} 15-28$, and $10 \mathrm{mg} / \mathrm{kg}$ per $\mathrm{d}$ thereafter. The solutions contained NTA in a range of $2: 1$ up to 2.5:1 molar ratio to iron. One group of control rats (NTA controls) received daily injections of an equivalent dose of NTA (60 $\mathrm{mM}): 17 \mathrm{mg} / \mathrm{kg}$ per $\mathrm{d}$ for $\mathrm{d} 1-14,47 \mathrm{mg} / \mathrm{kg}$ per $\mathrm{d}$ for $\mathrm{d} 15-$ 28 , and $94 \mathrm{mg} / \mathrm{kg}$ per $\mathrm{d}$ thereafter. An additional group of rats (untreated controls) received no injections. Solutions of FeNTA were prepared fresh daily by mixing reagent grade $\mathrm{FeSO}_{4} \cdot 7 \mathrm{H}_{2} \mathrm{O}$ with chilled $\left(5^{\circ} \mathrm{C}\right)$ disodium NTA stock solutions and were injected within $30 \mathrm{~min}$ of preparation. For studies of hepatic microsomal lipid peroxidation, rats at the start of the injection period weighed $\sim 200 \mathrm{~g}$ and were injected for $49 \mathrm{~d}$, receiving a total of $120 \mathrm{mg}$ of iron. For studies of hepatic mitochondrial lipid peroxidation, rats initially weighed $\sim 100 \mathrm{~g}$ and were injected for $35 \mathrm{~d}$, receiving cumulatively $45 \mathrm{mg}$ of iron. To identify possible acute effects of parenteral iron administration on hepatic mitochondrial lipid peroxidation, a group of normal rats $(200 \mathrm{~g})$ was injected with $10 \mathrm{mg} \mathrm{Fe} / \mathrm{kg}$ i.p. as FeNTA $24 \mathrm{~h}$ before death; control rats received an equivalent dose of NTA alone.

Dietary carbonyl iron overload. The diets that were supplemented with carbonyl iron were purchased from ICN Nutritional Biochemicals (Cleveland, Ohio). These diets con- taining $2.5 \%(w t / w t)$ carbonyl iron were prepared by adding carbonyl iron to a semipurified control diet (American Institute of Nutrition AIN-76 semipurified diet). Animals used as controls were fed the AIN-76 diet without added carbonyl iron. Rats that initially weighed $50-70 \mathrm{~g}$ were fed the $2.5 \%$ carbonyl iron diet or the control diet for periods of 28-44 $\mathrm{d}$ before death.

Preparation of hepatic microsomal fraction. Experimental and control rats from each group were treated identically. After an overnight fast, rats were killed either by decapitation or by exsanguination via cardiac puncture while under light ether anesthesia. The liver was quickly excised, weighed, and divided into two samples, one of which was immediately ( $<30 \mathrm{~s}$ after excision) immersed in an ice-cold solution of $0.154 \mathrm{M} \mathrm{KCl}, 0.003 \mathrm{M}$ EDTA, $\mathrm{pH}$ 7.4. After coarse slicing, $2 \mathrm{~g}$ of liver was used to make a $5 \%$ (wt/vol) whole liver homogenate with a Teflon-glass Potter-Elvehjem homogenizer. This homogenate was centrifuged at $3,020 \mathrm{~g}$ for $10 \mathrm{~min}\left(0-4^{\circ} \mathrm{C}\right)$ in an SS-34 rotor of a Sorvall RC-2 centrifuge (DuPont de Nemours, E. I. \& Co., Inc./Sorvall Instruments Div., Newtown, CT). The postmitochondrial supernatant fraction was centrifuged at $80,000 \mathrm{~g}$ for $30 \mathrm{~min}\left(0-4^{\circ} \mathrm{C}\right)$ in a Beckman L5-65B ultracentrifuge (Beckman Instruments, Inc., Fullerton, CA) by using an SW 50.1 rotor. The second sample of liver was divided for light microscopy, electron microscopy, and quantitative nonheme iron determination.

Preparation of hepatic mitochondrial fraction. Experimental and control rats from each group were treated identically as above except that the homogenizing solution was $0.25 \mathrm{M}$ sucrose, $0.003 \mathrm{M}$ EDTA, $\mathrm{pH}$ 7.4. After coarse slicing, $4 \mathrm{~g}$ of liver was used to make a $10 \%$ (wt/vol) whole liver homogenate with a Teflon-glass Potter-Elvehjem homogenizer. This homogenate was centrifuged at $600 \mathrm{~g}$ for $10 \mathrm{~min}$ $\left(0-4^{\circ} \mathrm{C}\right)$ in an HS-4 rotor in a Sorvall RC-2 centrifuge. The mitochondrial fraction was prepared by centrifugation of the postnuclear supernatant at $4,800 \mathrm{~g}$ for $13 \mathrm{~min}\left(0-4^{\circ} \mathrm{C}\right)$. The second sample of liver was divided for light microscopy, electron microscopy, and quantitative nonheme iron determination.

Previous experiments in this laboratory have indicated that with the centrifugal force conditions used above in normal liver, the isolated microsomal pellet contains $75 \%$ of the microsomes and $<5 \%$ of the mitochondria, whereas the isolated mitochondrial pellet contains $95 \%$ of the mitochondria and $<20 \%$ of the microsomes present in the initial whole liver homogenate.

Determination of lipid peroxidation in vivo. The sedimented microsomal and mitochondrial fractions from treated and control rats were assayed for the presence of lipid-conjugated dienes according to the method of Recknagel and Ghoshal (23). Lipids were extracted from the respective subcellular pellets with chloroform/methanol $(2: 1)$ according to the method described by Folch et al. (24) with the modification of Bligh and Dyer (25). The lipid in chloroform was dried under a stream of oxygen-free nitrogen. The chloroform-free lipid was then redissolved in cyclohexane $(1.5 \mathrm{ml}$, spectrophotometric grade) and absorbance from 220 to 275 nm was recorded against a cyclohexane blank with a Gilford 250 split-beam spectrophotometer (Gilford Instrument Laboratories Inc., Oberlin, $\mathrm{OH}$ ). During UV (ultraviolet) spectral analysis, the concentration of lipid in cyclohexane was $\sim 1 \mathrm{mg} / \mathrm{ml}$. After the UV measurements $250-\mu \mathrm{l}$ aliquots from each sample were assayed for total lipid content by the method described by Chiang et al. (26). All absorbance measurements were then normalized to a uniform denominator of $1 \mathrm{mg}$ lipid $/ \mathrm{ml}$ of cyclohexane. Estimation of lipid peroxidation depends on determination of the mean difference 
spectrum from 220 to $275 \mathrm{~nm}$ between lipids from treated animals and lipids from control animals (21). Results are presented both as the UV spectra from treated and control animals with the resultant mean difference spectrum (Fig 4), and as the difference in absorbance at $230 \mathrm{~nm} / \mathrm{mg}$ of lipid of the treated animals compared with the respective controls (Tables I and II).

Additions of iron to whole liver homogenates in vitro. EDTA was added to the homogenization medium to chelate any ionic iron that may be present during the homogenization or centrifugation procedures thereby preventing ironinduced lipid peroxidation from occurring in vitro after death. To confirm that iron-induced lipid peroxidation did not occur in vitro after death the following experiments were performed. Normal male Sprague-Dawley rats (150-350 g) were killed and whole liver homogenates were prepared as previously described (either in $0.25 \mathrm{M}$ sucrose or $0.154 \mathrm{M}$ $\mathrm{KCl}$ with $0.003 \mathrm{M}$ EDTA, $\mathrm{pH}$ 7.4). Iron was added in a protein-bound form as HSF and in an ionic-chelate form as FeNTA. The iron additions were made in several concentrations that were calculated to be comparable with the mean hepatic nonheme iron concentrations that had been achieved in vivo. For example, in studies of hepatic microsomal lipid peroxidation in vivo, livers with three different mean hepatic nonheme iron concentrations were used $(2,332,2,690$, and $4,161 \mu \mathrm{g} \mathrm{Fe} / \mathrm{g}$ liver; see Tables I and II). Therefore, for the in vitro experiments in which microsomes were examined, iron as HSF was added to homogenates to achieve the lower and the higher concentrations of iron; $2,300 \mu \mathrm{g} / \mathrm{g}$ liver and $4,150 \mu \mathrm{g} / \mathrm{g}$ liver. Similarly, for studies of hepatic mitochondrial lipid peroxidation in vivo, livers were used from rats that had achieved three different mean hepatic nonheme iron concentrations $(1,197,3,231$, and $4,216 \mu \mathrm{g} \mathrm{Fe} / \mathrm{g}$ liver; see Tables I and II). For the in vitro experiments in which mitochondria were examined, iron as ferritin was added at $1,200 \mu \mathrm{g} / \mathrm{g}$ liver and $4,225 \mu \mathrm{g} / \mathrm{g}$ liver. An equal volume of normal saline $(0.9 \% \mathrm{wt} / \mathrm{vol})$ was added to normal homogenates used as controls. For the in vitro additions of FeNTA, iron was added to whole liver homogenates in amounts equivalent to the mean hepatic nonheme iron concentrations present from rats that had received parenteral FeNTA (see Table I). FeNTA was prepared fresh at $5^{\circ} \mathrm{C}$ with a $2: 1$ molar excess of NTA. An equivalent volume of NTA alone was added to normal homogenates used as controls. These additions are summarized in Table III

After adding either ferritin, saline, FeNTA, or NTA, the homogenates were thoroughly mixed and the subcellular fractions were prepared as previously described. The lipids were extracted and the assay for conjugated dienes was performed as described above for the in vivo iron-overload studies. Conjugated dienes are expressed as the change in absorbance at $230 \mathrm{~nm} / \mathrm{mg}$ of lipid of the treated homogenates compared with the respective controls.

Tissue iron. Liver nonheme iron concentrations were determined by the method of Torrance and Bothwell (27) and expressed as micrograms $\mathrm{Fe}$ /gram liver (wet weight).

Light microscopy. Blocks of liver were fixed in $10 \%$ neutral buffered formalin, dehydrated with a graded series of ethyl alcohol, and embedded in paraffin. $5-\mu \mathrm{m}$ sections were prepared and stained with hematoxylin and eosin. Perl's Prussian blue stain for trivalent iron was used to assess storage iron content (28).

Electron microscopy. Blocks of liver were fixed in 2.5\% glutaraldehyde, postfixed in osmium tetroxide, dehydrated with a graded series of acetone, and embedded in Araldite (R. P. Cargille Laboratories, Inc., Cedar Grove, NJ). 1- $\mathrm{mm}$ sections were stained with methylene blue and viewed by light microscopy. Representative areas were further sectioned (ultrathin) for electron microscopy. Ultrathin sections were stained with uranyl acetate and lead citrate.

Statistical methods. All data are expressed as mean \pm SEM. Significance of differences was assessed by the Student's $t$ test, or where applicable the Welch's $t$ test (29).

\section{RESULTS}

\section{Hepatic iron distribution and concentration}

Parenteral FeNTA. Light microscopy (Perl's Prussian blue stain) showed iron overload of parenchymal cells and Kupffer cells with uniform distribution throughout the hepatic lobules (Fig. 1). Electron microscopy showed increased amounts of iron as crystalline ferritin and amorphous hemosiderin. Rats that were used for experiments of microsomal lipid peroxidation achieved mean hepatic nonheme iron concentrations of $2,332 \pm 118 \mu \mathrm{g} / \mathrm{g}(n=5)$ after $49 \mathrm{~d}$ of FeNTA injections. Rats that were used for experiments of mitochondrial lipid peroxidation achieved mean hepatic nonheme iron concentrations of $1,197 \pm 63 \mu \mathrm{g} /$ $\mathrm{g}(\boldsymbol{n}=12)$ after $35 \mathrm{~d}$ of FeNTA injections (Table I).

Dietary carbonyl iron. At the earlier time periods light microscopy showed iron overload almost entirely in hepatocytes in a periportal distribution. After 4 to $6 \mathrm{wk}$, some stainable iron was also seen in Kupffer cells, bile duct epithelium, endothelial cells, and occasionally in macrophages. The periportal to centrilobular gradient was still maintained (Fig. 2). Electron microscopy showed increased amounts of iron in the usual storage forms, namely crystalline ferritin and amorphous hemosiderin. There was no evidence of particulate or elemental iron (Fig. 3). Rats that were used for experiments of microsomal lipid peroxidation achieved mean hepatic nonheme iron concentrations of $2,690 \pm 98 \mu \mathrm{g} / \mathrm{g}(n=3)$ and $4,161 \pm 271 \mu \mathrm{g} / \mathrm{g}(n$ $=6$ ) after 28 and $44 \mathrm{~d}$, respectively, while being fed the carbonyl iron-supplemented diet. Rats used for experiments of mitochondrial lipid peroxidation achieved mean hepatic nonheme iron concentrations of $3,231 \pm 367 \mu \mathrm{g} / \mathrm{g}(n=3)$ and $4,216 \pm 218 \mu \mathrm{g} / \mathrm{g}(n$ $=6$ ) after 28 and $44 \mathrm{~d}$, respectively, while being fed the carbonyl iron-supplemented diet (Table II).

\section{Lipid peroxidation after iron overload in vivo}

Parenteral FeNTA. No evidence of conjugated diene formation was detected in liver microsomal lipids from FeNTA-treated rats. There was no significant difference spectrum between treated and control rats between 220 and $275 \mathrm{~nm}$ (Fig. 4A). The mean hepatic nonheme iron concentration for this group of ironoverloaded rats was $2,332 \pm 118 \mu \mathrm{g} / \mathrm{g}$ (Table I). 

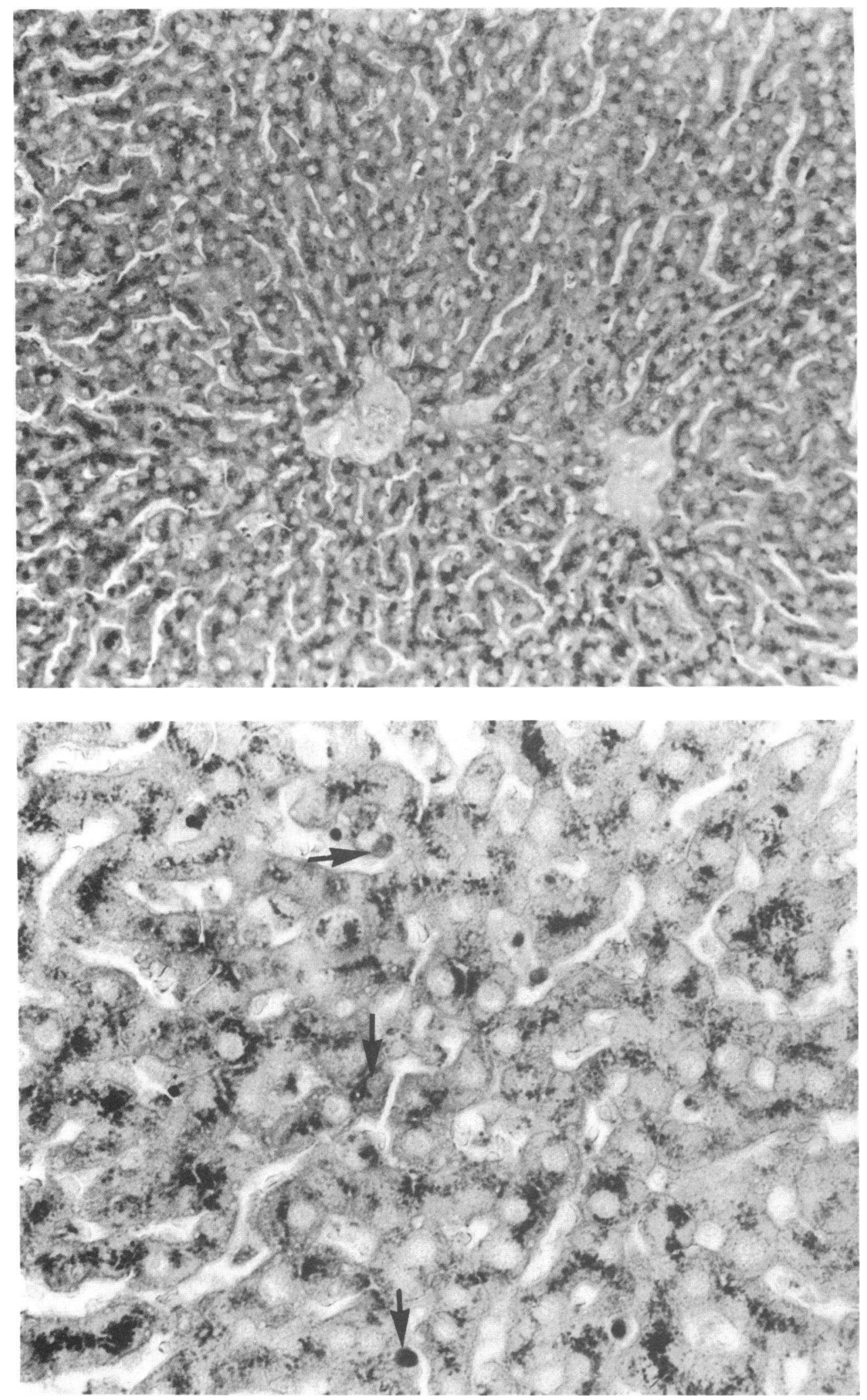
TABLE I

Hepatic Lipid Peroxidation In Vivo in Rats with Chronic Iron Overload

\begin{tabular}{|c|c|c|c|c|c|c|}
\hline Fraction & $n$ & $\begin{array}{l}\text { 1.iver iron } \\
\text { concentration }\end{array}$ & Total liver iron & $\begin{array}{c}\text { Absorbance at } \\
230 \mathrm{~nm} \text { per } \mathrm{mg} \text { lipid }\end{array}$ & $\begin{array}{c}\Delta \text { Absorbance at } \\
230 \mathrm{~nm} \text { per mg lipid }\end{array}$ & $\boldsymbol{P}$ \\
\hline & & $\mu \mathrm{Fe} / \mathrm{g}$ & $m g$ & & & \\
\hline \multicolumn{7}{|c|}{ Parenteral FeNTA (35 and $49 \mathrm{~d}$ ) } \\
\hline \multicolumn{7}{|l|}{ Microsomal } \\
\hline Iron overload & 5 & $2,332 \pm 118^{\circ}$ & - & $0.251 \pm 0.020^{\circ}$ & - & \\
\hline Control & 6 & $129 \pm 15$ & - & $0.216 \pm 0.010$ & 0.035 & NS \\
\hline \multicolumn{7}{|l|}{ Mitochondrial } \\
\hline Iron overload & 12 & $1,197 \pm 63$ & $12.34 \pm 0.60^{\circ}$ & $0.632 \pm 0.037$ & - & \\
\hline Control & 12 & $56 \pm 6$ & $0.57 \pm 0.08$ & $0.405 \pm 0.012$ & 0.227 & $<0.001$ \\
\hline \multicolumn{7}{|c|}{ Parenteral FeNTA (10 mg Fe $/ \mathrm{kg}$ ) $24 \mathrm{~h}$ before death } \\
\hline \multicolumn{7}{|l|}{ Mitochondrial } \\
\hline Treated & 3 & $115 \pm 23$ & $0.97 \pm 0.23$ & $0.468 \pm 0.016$ & - & \\
\hline Control & 3 & $39 \pm 5$ & $0.32 \pm 0.06$ & $0.434 \pm 0.009$ & 0.034 & NS \\
\hline
\end{tabular}

- Mean \pm SEM.

In contrast, mitochondrial lipids from FeNTAtreated rats showed a significantly positive mean difference spectrum with a peak at $225 \mathrm{~nm}$ (Fig. 4D). The mean hepatic nonheme iron concentration for this group of iron-overloaded rats was $1,197 \pm 63 \mu \mathrm{g} / \mathrm{g}$ and the $\Delta$ absorbance at $230 \mathrm{~nm}(0.227 / \mathrm{mg}$ lipid $)$ was highly significant $(P<0.001$; Table I).

There was no difference in UV absorbance between NTA and untreated controls. There was no evidence of conjugated diene formation in liver mitochondrial lipids after the acute $(24 \mathrm{~h})$ administration of FeNTA (Table I).

Dietary carbonyl iron. At a mean hepatic iron concentration of $2,690 \mu \mathrm{g} / \mathrm{g}$, no evidence of conjugated diene formation was detected in liver microsomal lipids from rats that had received the carbonyl iron-supplemented diet (Fig. 4B). However, at the higher mean hepatic iron concentration of $4,161 \mu \mathrm{g} / \mathrm{g}$, microsomal lipids showed a significantly positive mean difference spectrum demonstrating a peak at $230 \mathrm{~nm}$ (Fig. 4C) with a $\Delta$ absorbance at $230 \mathrm{~nm}$ of $0.185 / \mathrm{mg}$ lipid ( $P$ $<0.05$; Table II).

Hepatic mitochondrial lipids from rats with carbonyl iron overload showed a significantly positive mean difference spectrum at mean hepatic iron concentrations of 3,231 and $4,216 \mu \mathrm{g} / \mathrm{g}$ (Figs. $4 \mathrm{E}$ and F).
At both iron concentrations the mean difference spectra showed peaks at $230 \mathrm{~nm}$ with a $\Delta$ absorbance at $230 \mathrm{~nm}$ of $0.142 / \mathrm{mg}$ lipid $(P<0.001)$ at the lower iron concentration, and a $\Delta$ absorbance at $230 \mathrm{~nm}$ of 0.151 / mg lipid $(P<0.005)$ at the higher concentration (Table II).

In summary, increased lipid-conjugated diene formation was detected in lipids from mitochondria at all three hepatic iron concentrations studied in both models of experimental chronic iron overload in vivo. In contrast, increased lipid-conjugated diene formation was detected in microsomal lipids only at the higher liver iron concentration achieved by dietary carbonyl iron supplementation. Conjugated diene formation was not observed in liver mitochondrial lipids after a single injection of FeNTA $24 \mathrm{~h}$ before death (Tables I and II).

\section{Addition of iron to whole liver homogenates in vitro}

No significant conjugated diene formation was observed in either microsomes or mitochondria when iron, either in a protein-bound (ferritin) or in an ionicchelate form (FeNTA) was added to normal liver homogenates. These data are summarized in Table III.

FigURE 1 Light microscopy of rat liver after parenteral FeNTA. These photomicrographs (Perl's Prussian blue stain for trivalent iron) are of liver tissue from a rat that had been injected with FeNTA for $49 \mathrm{~d}$. A liver nonheme iron concentration of $2,242 \mu \mathrm{g} / \mathrm{g}$ was achieved. At the lower power $(\times 140$, top) iron can be seen evenly distributed throughout the hepatic lobule. At the higher power $(\times 450$, bottom) iron can be seen in both Kupffer cells (arrows) and hepatocytes. 

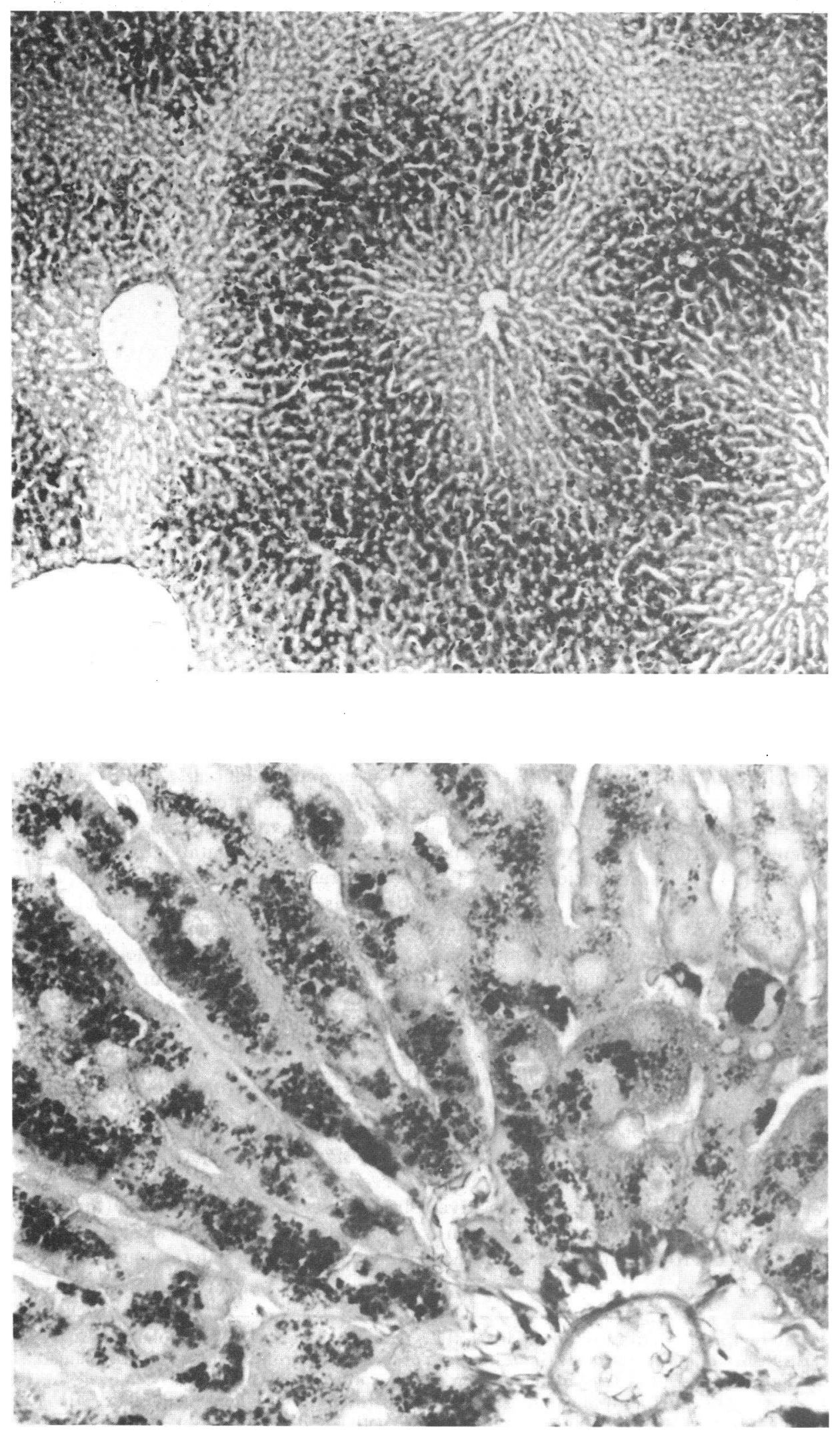


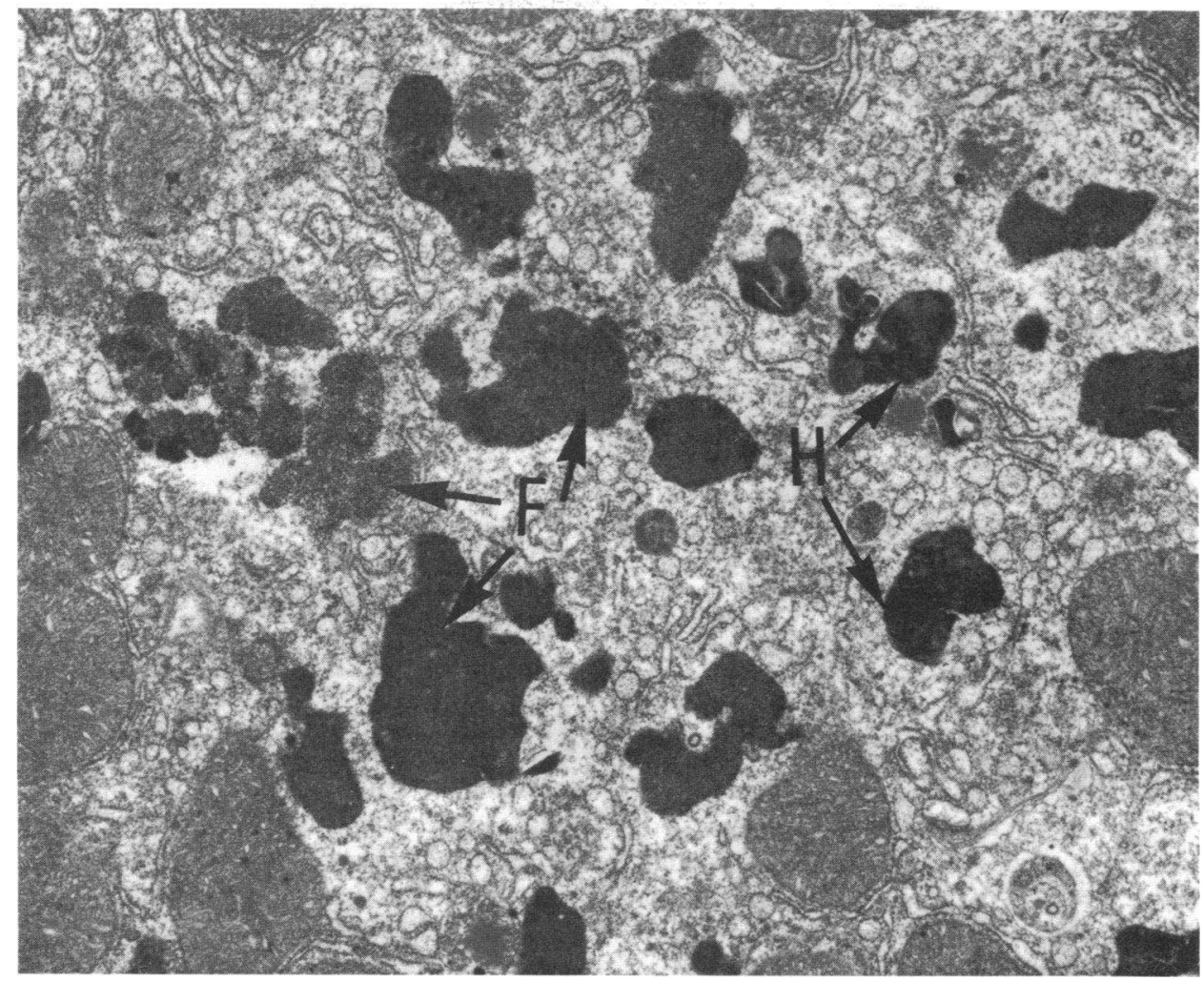

FigURE 3 Electron microscopy of rat hepatocyte after dietary carbonyl iron. This electron micrograph is from a liver specimen from a rat that received the $2.5 \%$ carbonyl iron diet for $35 \mathrm{~d}$ and achieved a liver iron concentration of $3,726 \mu \mathrm{g} / \mathrm{g}(\times 22,200)$. This demonstrates the usual storage forms of iron, namely crystalline ferritin $(\mathbf{F})$ and amorphous hemosiderin $(\mathbf{H})$ in a hepatocyte. There was no evidence of particulate or elemental iron.

\section{DISCUSSION}

These data presented above from two models of experimental chronic iron overload demonstrate the presence of lipid-conjugated dienes in both mitochondrial and microsomal lipids, and are consistent with the hypothesis that excessive hepatic iron induces lipid peroxidation in vivo. The demonstration of lipid-conjugated dienes in hepatic organelles extracted from liver homogenates subjected only to differential centrifugation is a direct measure of the occurrence of in vivo lipid peroxidation $(23,30)$. That the conjugated diene formation did not occur in vitro after death under the influence of ambient tissue iron is demonstrated by the failure to induce the formation of con- jugated dienes by exposing normal liver homogenates to varying amounts of either ionic-chelate (FeNTA) or protein-bound (ferritin) iron for periods of time similar to that needed to process the homogenates from iron-overloaded livers.

Parenteral administration of FeNTA resulted in moderate amounts of hepatic iron overload with iron deposition evenly distributed throughout the hepatic lobule in both parenchymal and reticuloendothelial cells. Lipid peroxidation was demonstrated only in mitochondria at a relatively low hepatic iron concentration. At a higher hepatic iron concentration no evidence of microsomal lipid peroxidation could be demonstrated in FeNTA-treated animals. In contrast, experimental chronic iron overload produced by dietary

Figure 2 Light microscopy of rat liver after dietary carbonyl iron. These photomicrographs (Perl's Prussian blue stain for trivalent iron) are of liver tissue from a rat that had been fed the $2.5 \%$ (wt/wt) carbonyl iron diet for $44 \mathrm{~d}$. A liver nonheme iron concentration of 3,927 $\mu \mathrm{g} / \mathrm{g}$ was achieved. At the lower power ( $\times 100$, top) increased iron deposition is seen in a periportal distribution. At the higher power $(\times 450$, bottom) iron can be seen primarily in hepatocytes with some in Kupffer cells. 
TABLE II

Hepatic Lipid Peroxidation In Vivo in Rats with Chronic Iron Overload: Dietary Carbonyl Iron (28 and $44 d$ )

\begin{tabular}{|c|c|c|c|c|c|c|}
\hline Fraction & $n$ & $\begin{array}{l}\text { Liver iron } \\
\text { concentration }\end{array}$ & Total liver iron & $\begin{array}{l}\text { Absorbance at } \\
230 \mathrm{~nm} \text { per } \mathrm{mg} \text { lipid }\end{array}$ & $\begin{array}{c}\Delta \text { Absorbance at } \\
230 \mathrm{~nm} \text { per mg lipid }\end{array}$ & $\boldsymbol{P}$ \\
\hline & & $\mu \mathrm{Fe} / \mathrm{g}$ & $m g$ & & & \\
\hline \multicolumn{7}{|l|}{ Microsomal } \\
\hline Iron overload & 3 & $2,690 \pm 98^{\circ}$ & $18.82 \pm 1.32^{\circ}$ & $0.255 \pm 0.017^{\bullet}$ & - & \\
\hline Control & 3 & $144 \pm 17$ & $0.83 \pm 0.10$ & $0.229 \pm 0.011$ & 0.026 & NS \\
\hline Iron overload & 6 & $4,161 \pm 271$ & $20.05 \pm 0.75$ & $0.510 \pm 0.067$ & - & \\
\hline Control & 6 & $18 \pm 3$ & $0.18 \pm 0.03$ & $0.325 \pm 0.016$ & 0.185 & $<0.05$ \\
\hline \multicolumn{7}{|l|}{ Mitochondrial } \\
\hline Iron overload & 3 & $3,231 \pm 367$ & $22.02 \pm 1.88$ & $0.608 \pm 0.008$ & - & \\
\hline Control & 3 & $48 \pm 13$ & $0.27 \pm 0.08$ & $0.466 \pm 0.008$ & 0.142 & $<0.001$ \\
\hline Iron overload & 6 & $4,216 \pm 218$ & $17.52 \pm 1.01$ & $0.592 \pm 0.014$ & - & \\
\hline Control & 6 & $18 \pm 3$ & $0.17 \pm 0.02$ & $0.441 \pm 0.025$ & 0.151 & $<0.005$ \\
\hline
\end{tabular}

- Mean \pm SEM.

supplementation with carbonyl iron resulted in much higher hepatic iron concentrations than those observed after FeNTA administration. Furthermore, virtually all of the iron was present in hepatocytes, a pattern which is analogous to that seen in human hereditary hemochromatosis. Using this new model of dietary iron overload, we have demonstrated hepatic lipid peroxidation in a mitochondrial fraction at hepatic iron con- centrations $>3,000 \mu \mathrm{g} / \mathrm{g}$ liver. In contrast, microsomal lipid peroxidation was demonstrated only at the higher hepatic iron concentration of $\sim 4,000 \mu \mathrm{g} / \mathrm{g}$, suggesting either different degrees of organelle membrane susceptibility or differential effects due to subcellular compartmentation of intracellular iron.

Many of the previous studies of the cellular effects of chronic iron overload have been based on experi-

TABLE III

Hepatic Lipid Peroxidation In Vitro: Iron Added to Rat Liver Homogenates

\begin{tabular}{|c|c|c|c|c|c|}
\hline Fraction & $n$ & $\begin{array}{l}\text { Final concentration } \\
\text { of added iron }\end{array}$ & $\begin{array}{l}\text { Absorbance at } 230 \\
\mathrm{~nm} \text { per } \mathrm{mg} \text { lipid }\end{array}$ & $\begin{array}{c}\Delta \text { Absorbance at } \\
230 \mathrm{~nm} \text { per } \mathrm{mg} \text { lipid }\end{array}$ & $P$ \\
\hline & & $\mu \mathrm{g} \mathrm{Fe} / \mathrm{g}$ liver & & & \\
\hline \multicolumn{6}{|l|}{ Microsomal } \\
\hline Ferritin & 3 & 2,300 & $0.311 \pm 0.012^{\circ}$ & - & \\
\hline Saline & 3 & - & $0.263 \pm 0.024$ & 0.048 & NS \\
\hline Ferritin & 3 & 4,160 & $0.272 \pm 0.025$ & - & \\
\hline Saline & 3 & - & $0.261 \pm 0.014$ & 0.011 & NS \\
\hline FeNTA & 3 & 2,300 & $0.301 \pm 0.029$ & 一 & \\
\hline NTA & 3 & - & $0.255 \pm 0.009$ & 0.046 & NS \\
\hline \multicolumn{6}{|c|}{ Mitochondrial } \\
\hline Ferritin & 3 & 1,200 & $0.488 \pm 0.027$ & - & \\
\hline Saline & 3 & - & $0.455 \pm 0.007$ & 0.033 & NS \\
\hline Ferritin & 3 & 4,200 & $0.457 \pm 0.022$ & 一 & \\
\hline Saline & 3 & - & $0.413 \pm 0.007$ & 0.044 & NS \\
\hline FeNTA & 5 & 1,200 & $0.419 \pm 0.025$ & 一 & \\
\hline NTA & 6 & - & $0.416 \pm 0.018$ & 0.003 & NS \\
\hline
\end{tabular}

- Mean \pm SEM. 

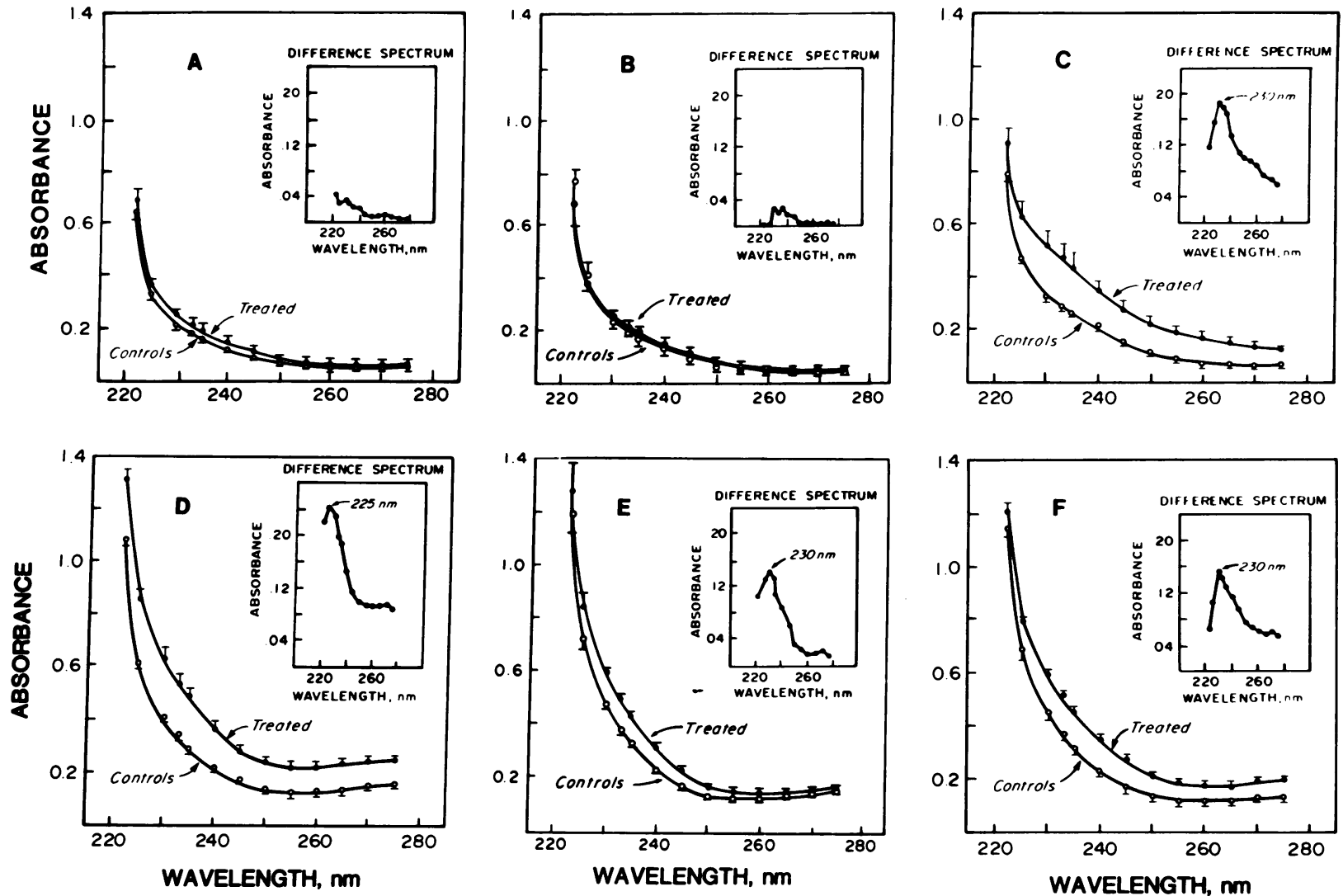

FIGURE 4 Iron-induced hepatic lipid peroxidation in vivo. The UV absorption spectra and mean difference spectra are shown for rat liver microsomal $(A, B, C)$ and mitochondrial (D, E, F) lipids. A and D are from rats that received parenteral FeNTA and B, C, E, and F are from rats that received dietary carbonyl iron. Each point is the mean absorbance per milligram lipid per milliliter cyclohexane for that wavelength, and the bar represents the SEM. The difference spectrum is calculated by subtracting the mean absorbance (per milligram lipid for each wavelength) of lipids from controls, from that of treated animals. There is no significant difference in absorbance in microsomal lipids at mean hepatic nonheme iron concentrations of $2,332 \mu \mathrm{g} / \mathrm{g}$ and $2,690 \mu \mathrm{g} / \mathrm{g}$ (A and B). However, at the higher hepatic iron concentration $(4,161 \mu \mathrm{g} / \mathrm{g} ; \mathrm{C})$, there is a significant difference in absorbance with a peak at $230 \mathrm{~nm}$. In mitochondrial lipids a difference in absorbance was detected at all three hepatic iron concentrations studied $(1,197,3,231,4,216 \mu \mathrm{g} / \mathrm{g} ; \mathrm{D}, \mathrm{E}$, and $\mathrm{F}$, respectively), indicative of conjugated diene formation.

ments of in vitro susceptibility to lipid peroxidation. Wills (31) found increased MDA production in ironloaded mouse liver microsomes incubated in vitro in the presence of ascorbate and an NADPH-generating system. Similarly, Heys and Dormandy (32) found increased susceptibility to in vitro peroxidation in ironoverloaded spleens from thalassemic patients. Lee et al. (33), in studying the response of glutathione peroxidase and catalase to dietary iron overload in rats, demonstrated increased in vitro lipid peroxidation in whole liver homogenates from rats that had achieved minimal hepatic iron overload $(2-3 \times$ control). In these types of experiments it is possible that iron released from storage sites provided the catalytic stimulus to the in vitro system (18) and the question of whether in vivo lipid peroxidation had already occurred remained unanswered. Two additional studies $(19,20)$ have provided evidence of iron-induced hepatic lipid peroxidation on the basis of increased MDA formation in liver homogenates (19) and in mitochondria (20) after iron dextran was administered in vivo. Hanstein et al. (20) have also demonstrated mild mitochondrial functional abnormalities (decreased respiratory control ratio and decreased phosphorylation efficiency) that were thought to have developed from peroxidative damage to mitochondrial membranes in vivo. 
Other investigators have measured ethane and pentane evolution in breath as indicants of in vivo peroxidative breakdown of lipids in conditions of parenteral iron overload (34-36). However, in these experimental circumstances it is not possible to determine the specific sites of lipid peroxidation, nor is it clear to what extent overproduction or diminished metabolic elimination contribute to the increased rate of appearance of these exhaled alkanes (37).

Another mechanism whereby chronic iron overload may cause hepatocellular injury is that due to diminished lysosomal membrane integrity, which has been demonstrated in liver biopsy tissue from patients with hereditary and secondary hemochromatosis (8). The way in which lysosomal membranes are disrupted in iron overload states is unknown and whether the disruption comes from within the lysosome (perhaps caused by some toxic effect of excess hemosiderin) or from a biochemical process such as lipid peroxidation initiated by iron within the cytosol remains to be elucidated. We recognize that our mitochondrial fractions may have some lysosomal contamination because of the known difficulties in preparing pure fractions of mitochondria $(20,38)$, and this may be a factor in demonstrating evidence of iron-induced lipid peroxidation in these organelles. However, Arborgh et al. (39) have demonstrated in iron-overloaded rat liver that the lipid content of mitochondria is $\sim 100$ times that of lysosomes $(4.04 \mathrm{mg}$ phospholipid/g liver in mitochondria vs. $0.056 \mathrm{mg} / \mathrm{g}$ in lysosomes), suggesting that the contribution of lysosomes to the lipid component of our mitochondrial fraction was minimal and could not generate sufficient lipid-conjugated dienes to account for the positive mean difference spectra that we observed. Therefore our data demonstrate that mitochondrial membranes have undergone peroxidative decomposition in vivo, although we cannot exclude some small contribution from lysosomal membrane lipids in the overall degradation process.

Our findings support the hypothesis that iron-induced membrane lipid peroxidation occurs in vivo in chronic hepatic iron overload. Iron-induced peroxidative damage may occur via a number of possible mechanisms. In conditions of iron overload, the ability of the hepatocyte to maintain iron in the nontoxic protein-bound ferric state may be exceeded, resulting either in small amounts of ferrous iron or in excessive amounts of low molecular weight chelate iron in the cytosol (40). Iron in these forms may play a role in the generation of free hydroxyl radicals $(\mathrm{OH} \cdot)$ by catalysing the reaction of superoxide radical $\left(\mathrm{O}_{2}^{-} \cdot\right)$ with hydrogen peroxide $\left(\mathrm{H}_{2} \mathrm{O}_{2}\right)$. This iron-dependent reaction has been postulated as a feasible mechanism of hydroxyl radical-induced lipid peroxidation in vivo $(41,42)$. Alternatively, it has been suggested that free ferrous iron can serve as a direct initiator of membrane peroxidation (18). In the presence of NADPH, concentrations of $\mathrm{Fe}^{2+}$ as low as $1 \mu \mathrm{M}$ resulted in peroxidation of liver microsomal membranes. Complete inhibition of peroxidation was observed when EDTA was added, thus demonstrating the requirement for free ferrous iron. Two proposed mechanisms whereby free ferrous iron could initiate lipid peroxidation are the formation of perferryl ion, $\mathrm{FeO}_{2}{ }^{2+}$, or the formation of a ternary free radical complex between arachidonic acid, ferrous iron, and oxygen, resulting in peroxidation of the hydrocarbon chain (18).

In conclusion, using two models of experimental chronic iron overload, we have demonstrated direct evidence of in vivo hepatic lipid peroxidation in both mitochondrial and microsomal membrane lipids. These findings may provide an explanation for certain of the initiating factors in hepatocellular damage that lead to the pathological manifestations seen in chronic iron overload states in man.

\section{ACKNOWLEDGMENTS}

The authors thank Dr. John W. Harris for his helpful suggestions and Mary Sue Rose, Patricia Rybicki, and Linda Hrabak for their expert technical assistance.

This work was supported in part by the Cuyahoga County Hospital Foundation and by grants from the U. S. Public Health Service (R01 AM 25105, R01 HL 24198, R01 ES 01821, R01 AM 31505, and T32 HL 07147). Dr. Bacon was a Post-Doctoral Research Fellow of the American Liver Foundation and is a Teaching and Research Scholar of the American College of Physicians.

\section{REFERENCES}

1. Powell, L. W., M. L. Bassett, and J. W. Halliday. 1980. Hemochromatosis: 1980 update. Gastroenterology. 78: 374-381.

2. Isaacson, C., H. C. Seftel, K. J. Keeley, and T. H. Bothwell. 1961. Siderosis in the Bantu: the relationship between iron overload and cirrhosis. J. Lab. Clin. Med. 58: 845-953.

3. Bomford, A., and R. Williams. 1976. Long-term results of venesection therapy in idiopathic haemochromatosis. Q. J. Med. (New Series). 45: 611-623.

4. Barry, M., D. M. Flynn, E. A. Letsky, and R. A. Risdon. 1974. Long-term chelation therapy in thalassaemia major: effect on liver iron concentration, liver histology and clinical progress. Br. Med. J. 2: 16-20.

5. Powell, L. W., and J. W. Halliday. 1980. Idiopathic haemochromatosis. In Iron in Biochemistry and Medicine. A. Jacobs and M. Worwood, editors. Academic Press, London. II: 461-498.

6. Jacobs, A. 1980. The pathology of iron overload. In Iron in Biochemistry and Medicine. A. Jacobs and M. Worwood, editors. Academic Press, London. II: 427-459.

7. Bonkowsky, H. L., J. F. Healey, P. R. Sinclair, J. F. Sinclair, and J. S. Pomeroy. 1981. Iron and the liver. Acute and long-term effects of iron-loading on hepatic haem metabolism. Biochem. J. 196: 57-64.

8. Peters, T. J., and C. A. Seymour. 1976. Acid hydrolase activities and lysosomal integrity in liver biopsies from 
patients with iron overload. Clin. Sci. Mol. Med. 50: 7578 .

9. Peters, T. J., C. Selden, and C. A. Seymour. 1977. Lysosomal disruption in the pathogenesis of hepatic damage in primary and secondary haemochromatosis. In Iron Metabolism. Chemical Industry in Basle Foundation Symposium, New Series, No. 5. Elsevier/North Holland, Amsterdam. 317-325.

10. Selden, C., M. Owen, J. M. P. Hopkins, and T. J. Peters. 1980. Studies on the concentration and intracellular localization of iron proteins in liver biopsy specimens from patients with iron overload with special reference to their role in lysosomal disruption. Br. J. Haematol. 44: 593-603.

11. Hunter, F. E., J. M. Gebicki, P. E. Hoffstein, J. Weinstein, and A. Scott. 1963. Swelling and lysis of rat liver mitochondria induced by ferrous ions. J. Biol. Chem. 238: 828-835.

12. Hochstein, P., K. Nordenbrand, and L. Ernster. 1964 Evidence for the involvement of iron in the ADP-activated peroxidation of lipids in microsomes and mitochondria. Biochem. Biophys. Res. Commun. 14: 323328.

13. McKnight, R. C., F. E. Hunter, and W. H. Oehlert. 1965. Mitochondrial membrane ghosts produced by lipid peroxidation induced by ferrous ion. I. Production and general morphology. J. Biol. Chem. 240: 3439-3446.

14. McKnight, R. C., and F. E. Hunter. 1966. Mitochondrial membrane ghosts produced by lipid peroxidation induced by ferrous ion. II. Composition and enzymatic activity. J. Biol. Chem. 241: 2757-2765.

15. Wills, E. D. 1969. Lipid peroxide formation in microsomes. General considerations. Biochem. J. 113: 315324.

16. Wills, E. D. 1969. Lipid peroxide formation in microsomes. The role of non-heme iron. Biochem. J. 113: 325332.

17. Wills, E. D. 1969. Lipid peroxide formation in microsomes. Relationship of hydroxylation to lipid peroxide formation. Biochem. J. 113: 333-342.

18. Kornbrust, D. J., and R. D. Mavis. 1980. Microsomal lipid peroxidation. I. Characterization of the role of iron and NADPH. Mol. Pharmacol. 17: 400-407.

19. Golberg, L., L. E. Marti, and A. Batchelor. 1962. Biochemical changes in the tissues of animals injected with iron. 3. Lipid peroxidation. Biochem. J. 83: 291-298.

20. Hanstein, W. G., T. D. Heitmann, A. Sandy, H. L. Biesterfeldt, H. H. Liem, and U. Müller-Eberhard. 1981. Effects of hexachlorobenzene and iron loading on rat liver mitochondria. Biochem. Biophys. Acta. 678: 293299.

21. Carbonyl iron powders. GAF Corporation, New York. 1-25.

22. May, M. E., R. T. Parmley, S. S. Spicer, D. P. Ravenel, E. E. May, and M. G. Buse. 1980. Iron nitrilotriacetateinduced experimental diabetes in rats. J. Lab. Clin. Med. 95: 525-535.

23. Recknagel, R. O., and A. K. Ghoshal. 1966. Quantitative estimation of peroxidative decomposition of rat liver microsomal and mitochondrial lipids after carbon tetrachloride poisoning. Exp. Mol. Pathol. 5: 413-426.

24. Folch, J., M. Lees, and S. G. H. Sloane. 1957. A simple method for the isolation and purification of total lipids from animal tissues. J. Biol. Chem. 226: 497-509.
25. Bligh, E. G., and W. J. Dyer. 1959. A rapid method of total lipid extraction and purification. Can. J. Biochem. Physiol. 37: 911-917.

26. Chiang, S. P., C. F. Gessert, and O. H. Lowry. 1957. Colorimetric determination of extracted lipids. Research Report 56-113, Air University School of Aviation Medicine, United States Air Force, Texas.

27. Torrance, J. D., and T. H. Bothwell. 1980. Tissue iron stores. In Iron. J. Cook, editor. Churchill-Livingstone, Inc., New York. 90-115.

28. Williams, R., P. J. Scheuer, and S. Sherlock. 1962. The inheritance of idiopathic haemochromatosis: a clinical and liver biopsy study of 16 families. Q. J. Med. 31: 249-265.

29. Snedecor, G. W., and W. G. Cochran. 1980. Statistical Methods. Iowa State University Press, Ames, Iowa. 7th edition. 83-106.

30. Waller, R. L., and R. O. Recknagel. 1977. Determination of lipid conjugated dienes with tetracyanoethylene $-{ }^{14} \mathrm{C}$ : significance for study of the pathology of lipid peroxidation. Lipids. 12: 914-921.

31. Wills, E. D. 1972. Effects of iron overload on lipid peroxide formation and oxidative demethylation by the liver endoplasmic reticulum. Biochem. Pharmacol. 21: 239-247.

32. Heys, A. D., and T. L. Dormandy. 1981. Lipid peroxidation in iron-overloaded spleens. Clin. Sci. (Lond.). 60: 295-301.

33. Lee, Y. H., D. K. Layman, R. R. Bell, and H. W. Norton. 1981. Response of glutathione peroxidase and catalase to excess dietary iron in rats. J. Nutr. 111: 2195-2202.

34. Dillard, C. J., and A. L. Tappel. 1979. Volatile hydrocarbon and carbonyl products of lipid peroxidation: a comparison of pentane, ethane, hexane and acetone as in vivo indices. Lipids. 14: 989-995.

35. Tappel, A. L., and C. J. Dillard. 1981. In vivo lipid peroxidation: measurement via exhaled pentane and protection by vitamin E. Fed. Proc. 40: 174-178.

36. Dougherty, J. J., W. A. Croft, and W. G. Hoekstra. 1981. Effects of ferrous chloride and iron-dextran on lipid peroxidation in vivo in vitamin $E$ and selenium adequate and deficient rats. J. Nutr. 111: 1784-1796.

37. Frank, H., T. Hintze, D. Bimboes, and H. Renner. 1980. Monitoring lipid peroxidation by breath analysis: endogenous hydrocarbons and their metabolic elimination. Toxicol. Appl. Pharmacol. 56: 337-344.

38. Dean, R. T., and A. J. Barrett. 1976. Lysosomes. In Essays in Biochemistry. P. N. Campbell and W. N. Aldridge, editors. Academic Press, London. 12: 1-40.

39. Arborgh, B. A. M., H. Glaumann, and J. L. E. Ericsson. 1974. Studies on iron loading of rat liver lysosomes. Chemical and enzymic composition. Lab. Invest. 30: 674-680.

40. Jacobs, A. 1977. Low molecular weight intracellular iron transport compounds. Blood. 50: 433-439.

41. Fong, K. L., P. B. McCay, J. L. Poyer, B. B. Keele, and H. Misra. 1973. Evidence that peroxidation of lysosomal membranes is initiated by hydroxyl free radicals produced during flavin enzyme activity. J. Biol. Chem. 248: $7792-7797$.

42. Halliwell, B. 1982. Superoxide-dependent formation of hydroxyl radicals in the presence of iron salts is a feasible source of hydroxyl radicals in vivo. Biochem. J. 205: 461-462. 